\title{
Role of CT scan in Diagnosis of Patients with Suspected Subacute Intestinal Obstruction
}

\author{
Archana Salvi ${ }^{1}$, Ashok Hadiya ${ }^{2}$ \\ ${ }^{1,2}$ Associate Professor, Department of Radiology, Gujarat Adani Institute of Medical Science, Bhuj, Kutch, Gujarat, India.
}

\section{Abstract}

Background: Intestinal obstruction is defined as mechanical or functional obstruction of the intestines which prevents the normal passage of the products of digestion. Present study was performed to study the role of Computerized Tomography (CT) in Diagnosis of patients with suspected subacute intestinal obstruction (SAIO), to find out site \& cause of obstruction and to diagnose complications of obstruction. Subjects and Methods: This study was conducted at Department of Radiodiagnosis, Gujarat Adani Institute of Medical Science, Bhuj, Kutch, Gujarat. Total number of 15 patients with SAIO having equivocal findings on USG was included in this study. All the statistical tests were performed in SPSS version 15 software. Results: Age of the patients in the study range between 14 to 70 years. Out of 15 were 8 male \& 7 female patients. On CT scan all 15 patients were found to have obstruction with 12 patients having mechanical obstruction \& 3 patients having pseudo obstruction secondary to appendicitis, jejunal perforation. CT scan correctly diagnosed intestinal obstruction with its cause in 14 out of 15 patients. Most common cause of SAIO was ileal stricture followed by intussusceptions. Conclusion: The findings of the study show that CT is a valuable diagnostic procedure in patients with subacute intestinal obstruction with high sensitivity. It is a problem-solving tool in equivocal cases.

Keywords: Computerized Tomography, Intestinal obstruction, Intussusceptions, Kutch, pseudo obstruction.

Corresponding Author: Dr. Ashok Hadiya, Department of Radiology, Gujarat Adani Institute of Medical Science, Bhuj, Kutch, Gujarat, India.

Received: December 2018

Accepted: December 2018

\section{Introduction}

Intestinal obstruction is a common clinical abnormality that is usually suspected on the basis of clinical signs and patient history. Intestinal obstruction is defined as mechanical or functional obstruction of the intestines which prevents the normal passage of the products of digestion. ${ }^{[1]}$ Intestinal obstruction is the most common surgical disorder of the small intestine. ${ }^{[2,3]}$ Though the knowledge of intestinal obstruction dates back to third to fourth century BC, it still remains important cause of morbidity and mortality in the surgical practice. The diagnosis of intestinal obstruction is often immediately evident after thorough clinical examination \& plain radiography. ${ }^{[4]}$ But at times it poses a difficulty especially in patients presenting as SAIO with less severe, intermittent features that cause delay in diagnosis. So sub acute intestinal obstruction remains a diagnostic \& therapeutic problem. ${ }^{[5,6]}$

Coupled with clinical features, plain radiography can lead to conclusion in 46- $80 \%$ cases. Ultrasound plays only adjunctive role to plain radiography. ${ }^{[7]}$ In such equivocal cases CT has been found to be very useful. The diagnosis of small bowel obstruction due to adhesions is made when all other causes of obstruction have been ruled out at CT. Bowel obstruction is considered to be present at CT when distended bowel loops are seen proximal to collapsed loops. On CT scan, small bowel diameter of more than $2.5 \mathrm{~cm}$ is indicative of obstruction. CT has particular advantage to detect exact level \& cause of obstruction. ${ }^{[8-11]}$ Now a days CT is considered to be the most efficacious imaging technique for determining the cause of intestinal obstruction. However, the indications for the use of CT in patients with SAIO have not been fully defined. Accordingly, we did a prospective study to determine the role of CT in the diagnosis of patients with suspected subacute bowel obstruction in whom confident decisions of therapy could not be made on the basis of clinical, plain radiographic \& ultrasound findings. ${ }^{[12-17]}$

Objectives of the study were to study the role of CT in Diagnosis of patients with suspected subacute intestinal obstruction (SAIO), to find out site \& cause of obstruction and to diagnose complications of obstruction.

\section{Subjects and Methods}

This study was conducted at Department of Radiodiagnosis, Gujarat Adani Institute of Medical Science, Bhuj, Kutch, Gujarat. Total number of 15 patients with SAIO having equivocal findings on USG was included in this study. Inclusion Criteria were Patients who had no substantial evidence of intestinal obstruction following sonographic 
and radiological evaluation and Patients with Intermittent/recurrent symptoms.

Exclusion Criteria were Patients with sufficient evidence of intestinal obstruction following clinical, sonographic and radiological evaluation. Detailed clinical evaluation of the patients was done. Plain x-ray of abdomen in erect posture $\&$ abdominopelvic ultrasound were performed before CT scan. CT scans were performed on a GE lightspeed VCT 64 slice scanner and acquired in precontrast \& portovenous phase at $60 \mathrm{sec}$ after i.v. contrast administration (inj. Iohexol $3 \mathrm{ml} / \mathrm{sec}$ ). Oral contrast agent liq. Sodium diatrizoate $30 \mathrm{ml}$ diluted in $1000 \mathrm{ml}$ of water was given over 45 minutes prior to scan.

Helical scanning was performed at $120 \mathrm{kVp} \& 240 \mathrm{~mA}$. Large FOV was used with scanning from diaphragm to beneath the symphysis pubis with helical speed $0.6 \mathrm{sec}$, slice thickness $5 \mathrm{~mm}$, interval $5 \mathrm{~mm}$ which were used reconstruct $0.625 \mathrm{~mm}$ thickncss axial \& also coronal, sagittal images.

\section{Statistical Analysis}

Qualitative data will be expressed as percentages and proportions. Quantitative data will be expressed as mean and standard deviation. All the statistical tests was performed in SPSS version 15 software.

\section{Results}

We studied 15 patients of subacute intestinal obstruction with equivocal findings on plain radiography \& ultrasound. They were subjected to CT scan \& our study findings are as follows: Age of the patients in the study range between 14 to 70 years. Out of 15 were 8 male \& 7 female patients. [Table 1\&2] On CT scan all 15 patients were found to have obstruction with 12 patients having mechanical obstruction \& 3 patients having pseudo obstruction secondary to appendicitis, jejunal perforation. [Table 3] CT diagnoses of 13 out of 14 patients who underwent surgery \& biopsy were found to be correct on intraoperative findings. 1 patient was correctly diagnosed of strangulation with SMV thrombosis \& ileal gangrene which was confirmed intraoperatively. 1 patient incorrectly diagnosed as duodenal neoplastic thickening on $\mathrm{CT}$ was found to have cholecystitis with pyloric stricture intraoperatively.

The concordance between the operative findings and the CT scan findings was examined. CT scan correctly diagnosed intestinal obstruction with its cause in 14 out of 15 patients. Most common cause of SAIO was ileal stricture followed by intussusceptions.

Table 1: Age wise Distribution of study participants.

\begin{tabular}{|c|c|c|}
\hline Age group in years & Number & Percentage \\
\hline $14-30$ & 5 & 33.3 \\
\hline $31-45$ & 4 & 30.7 \\
\hline $46-60$ & 4 & 30.7 \\
\hline 60 above & 2 & 13.3 \\
\hline Total & 15 & 100 \\
\hline
\end{tabular}

Usefulness of CT scan in diagnosis \& management of patients with SAIO is proven and confirmed by the results of our study, in which CT diagnosis well correlated with final operative diagnosis in $93 \%$ of cases.

Table 2: Gender wise distribution of study participants

\begin{tabular}{|c|c|c|}
\hline Gender & Number & Percentage \\
\hline Male & 8 & 53.3 \\
\hline Female & 7 & 46.6 \\
\hline Total & 15 & 100 \\
\hline
\end{tabular}

Table 3: Distribution of the patients by type of obstruction

\begin{tabular}{|c|c|c|}
\hline Type of obstruction & Number & Percentage \\
\hline True & 13 & 86.6 \\
\hline Pseudo & 2 & 13.3 \\
\hline
\end{tabular}

\section{Discussion}

SAIO has been defined in many ways and characteristically it suggests incomplete \& intermittent obstruction.[5] It is characterized by continued passage of flatus and/or feces beyond 6-12 hrs. After onset of symptoms namely colicky abdominal pain, vomiting, and abdominal distension The intestinal obstruction can be of small intestine or large intestine. The causes of a small bowel obstruction can be divided into three categories:

1. Obstruction arising from extraluminal causes such as adhesions, hernias, carcinomas, and abscesses.

2. Obstruction intrinsic to the bowel wall (e.g., primary tumors).

3. Intraluminal obstruction (e.g., gallstones, enteroliths, foreign bodies, and bezoars).

Large bowel obstruction can be classified as dynamic (mechanical) or adynamic (pseudo-obstruction). Mechanical obstruction is characterized by blockage of the large bowel. Miscellaneous causes like intussusception, endometriosis, radiation enteropathy also comprise important cause of bowel obstruction. ${ }^{[6]}$

Amit ojha et $a 1,{ }^{[18]}$ performed a study to evaluate role of investigations in diagnosis \& management of SAIO. Their study concluded that CT scan is highly useful in diagnosing SAIO. Accordingly we compared our study findings with theirs. Our study confirmed the high sensitivity of CT scan in diagnosis of SAIO \& establishing its etiology. In both the studies most common cause of SAIO was ileal stricture. In comparison incidence of bowel wall thickening was less where as intussusceptions more in our study was. Remaining cases comprised of tuberculosis, appendicitis, jejunal perforation \& SMV thrombosis. As there was no negative CT scan in our study, so specificity of the CT remained unevaluated.

\section{Conclusion}

The findings of the study show that CT is a valuable diagnostic procedure in patients with subacute intestinal obstruction with high sensitivity. It is a problem-solving tool in equivocal cases. CT is not only useful in distinguishing mechanical obstruction from paralytic ileus but also it often establishes the cause of obstruction \& presence of complications like strangulation \& perforation. 
CT findings lead the surgeon to surgical management in significant number of patients.

\section{References}

1. Fitzgerald, J. Edwad F. Small bowel obstruction. Oxford: WilleyBlackwell. 2010, Pp 74-79.

2. Shelton AA, Thoedore RS, Welton ML. Small Intestine In: Way LW, Doherty GM, editors. Current Surgical Diagnosis and Treatment. New York: McGraw Hills; 2003, p 674-704.

3. Whang EE, Zinner MJ. Small Intestine. In: Charles BF, ed Schwartz principles of surgery. New York: McGraw Hill; 2005, p 1017-54

4. Courtney M. townsend, Jr. R Daniel Beauchamp. B. Mark Evers. Kenneth 1 Mattox. Sabiston textbook of Surgery, Elsevier 2016, pp $1247-1254$

5. Winslet MC. Intestinal Obstruction. In: Russel RCG, Norman WS, Bulstrode Christopher JK, eds. Bailey \& Love's Short Practice of Surgery. London: Arnold; 2004, p 1186-1202.

6. Tito WA, Sarr MG: intestinal obstruction. In Zuidema GD, editor: Surgery of the alimentary tract, Philadelphia, 1996, WB saunders pp 375-416.

7. Field S. The plain abdominal radiograph-The acute abdomen. In Grainger RG, Allison DJ (Eds): Diagnostic Radiology (3rd edn), Churchill Livingstone, Edinburgh,1997.

8. Fukuya T, Hawes DR, Lu CC, et al: CT diagnosis of small-bowel obstruction: Efficacy in 60 patients. AJR Am J Roentgenol 158:765769, discussion 771-772, 1992.
9. Mucha $P$ Small intestinal obstruction. Surg Clin northAM 1987:67:597-620

10. Richards WO, Williams LF. Obstruction of the small \& large intestine Surg clin north Am 1988;68:355-376

11. Tibbin S. Diagnosis of intestinal obstruction with special regard to plain roentgen examinations of the abdomen. Acta Chir Scand 1969:135:249-252

12. Shaff MI, Tarr RW, Partain CL, James AE. Computed tomography \& magnetic resonance imaging of acute abdomen. Surg clin north $\Lambda \mathrm{m}$ 1988:68:233-254

13. Megibow AJ, Balthazar EJ, Cho KC, Medwid SW, Birnbaum BA, Noz ME. Bowel obstruction; evaluation with CT. Radiology 1991:180:313-318.

14. Fukuya T, Hawes DR, LU CC, Chang PJ, Barloon TJ. CT diagnosis of small bowel obstruction; efficacy in 60 patients. AJR 1992;158:765-769.

15. Gazelle GS, Goldberg M $\Lambda$, Wittenberg $\mathrm{j}$, halpem EF, Pinkney L, Mueller PR, Efficacy of CT in distinguishing small bowel obstruction from other causes of small bowel dilatation. AJR 1994;162:43-47.

16. Balthazar EJ. CT of small bowel obstruction. AJR 1994;162:255-261

17. Carol M Rumack, Stephanie R Wilson, J. William Charboneau, Deborah Levine. Diagnostic Ultrasound Mosby Elsevier, 2011,pp 296-299.

18. Amit Ojha, Anjani Jalaj, Shaleen Tiwari, Vikram Mujalde, Prasheel. "Diagnosis and Management of Subacute Intestinal Obstruction: A Prospective Study". Journal of Evolution of Medical and Dental Sciences 2014; Vol. 3, Issue 26, June 30; Page: 7326- 7340, DOI: $10.14260 /$ jemds/2014/2898

Copyright: (C) the author(s), publisher. Asian Journal of Medical Radiological Research is an Official Publication of "Society for Health Care \& Research Development". It is an open-access article distributed under the terms of the Creative Commons Attribution Non-Commercial License, which permits unrestricted non-commercial use, distribution, and reproduction in any medium, provided the original work is properly cited.

How to cite this article: Salvi A, Hadiya A. Role of CT scan in Diagnosis of Patients with Suspected Subacute Intestinal Obstruction. Asian J. Med. Radiol. Res. 2018;6(2):17-19.

DOI: dx.doi.org/10.21276/ajmrr.2018.6.2.5

Source of Support: Nil, Conflict of Interest: None declared. 